\title{
Generalized Mixed Equilibrium Problems and Fixed Point Problem for a Countable Family of Total Quasi- $\phi$-Asymptotically Nonexpansive Mappings in Banach Spaces
}

\author{
Jinhua Zhu, ${ }^{1}$ Shih-Sen Chang, ${ }^{2}$ and Min Liu' ${ }^{1}$ \\ ${ }^{1}$ Department of Mathematics, Yibin University, Yibin, Sichuan 644007, China \\ ${ }^{2}$ Department of Mathematics, College of Statistics and Mathematics, \\ Yunnan University of Finance and Economics, Yunnan, Kunming 650221, China \\ Correspondence should be addressed to Shih-Sen Chang, changss@yahoo.cn \\ Received 4 September 2011; Accepted 25 October 2011 \\ Academic Editor: Giuseppe Marino
}

Copyright (C) 2012 Jinhua Zhu et al. This is an open access article distributed under the Creative Commons Attribution License, which permits unrestricted use, distribution, and reproduction in any medium, provided the original work is properly cited.

\begin{abstract}
The purpose of this paper is first to introduce the concept of total quasi- $\phi$-asymptotically nonexpansive mapping which contains many kinds of mappings as its special cases and then to use a hybrid algorithm to introduce a new iterative scheme for finding a common element of the set of solutions for a system of generalized mixed equilibrium problems and the set of common fixed points for a countable family of total quasi- $\phi$-asymptotically nonexpansive mappings. Under suitable conditions some strong convergence theorems are established in an uniformly smooth and strictly convex Banach space with Kadec-Klee property. The results presented in the paper improve and extend some recent results.
\end{abstract}

\section{Introduction}

Throughout this paper, we denote by $\mathbb{R}$ and $\mathbb{R}^{+}$the set of all real numbers and all nonnegative real numbers, respectively. We also assume that $E$ is a real Banach space, $E^{*}$ is the dual space of $E, C$ is a nonempty closed convex subset of $E$, and $\langle\cdot, \cdot\rangle$ is the pairing between $E$ and $E^{*}$. In the sequel, we denote the strong convergence and weak convergence of a sequence $\left\{x_{n}\right\}$ by $x_{n} \rightarrow x$ and $x_{n} \rightarrow x$, respectively, and $J: E \rightarrow 2^{E^{*}}$ is the normalized duality mapping defined by

$$
J(x)=\left\{x^{*} \in E^{*}:\left\langle x, x^{*}\right\rangle=\|x\|=\left\|x^{*}\right\|\right\}, \quad x \in E .
$$


Let $\psi: C \rightarrow \mathbb{R}$ be a proper real-valued function, $A: C \rightarrow E^{*}$ a nonlinear mapping, and $F: C \times C \rightarrow \mathbb{R}$ a bifunction. The "so called" generalized mixed equilibrium problem for $F, A, \psi$ is to find $x^{*} \in C$ such that

$$
F\left(x^{*}, y\right)+\left\langle A x^{*}, y-x^{*}\right\rangle+\psi(y)-\psi\left(x^{*}\right) \geq 0, \quad \forall y \in C
$$

We denote the set of solutions of (1.2) by $\operatorname{GMEP}(F, A, \psi)$, that is,

$$
\operatorname{GMEP}(F, A, \psi)=\left\{x^{*} \in C: F\left(x^{*}, y\right)+\left\langle A x^{*}, y-x^{*}\right\rangle+\psi(y)-\psi\left(x^{*}\right) \geq 0, \forall y \in C\right\}
$$

\section{Special Examples}

(i) If $A=0$, then the problem (1.2) is reduced to the mixed equilibrium problem $(\mathrm{MEP})$, and the set of its solutions is denoted by

$$
\operatorname{MEP}(F, \psi)=\left\{x^{*} \in C: \Theta\left(x^{*}, y\right)+\psi(y)-\psi\left(x^{*}\right) \geq 0, \forall y \in C\right\}
$$

(ii) If $\psi \equiv 0$, then the problem (1.2) is reduced to the generalized equilibrium problem (GEP), and the set of its solutions is denoted by

$$
\operatorname{GEP}(F, A)=\left\{x^{*} \in C: F\left(x^{*}, y\right)+\left\langle A x^{*}, y-x^{*}\right\rangle \geq 0, \forall y \in C\right\}
$$

(iii) If $A=0, \psi=0$, then the problem (1.2) is reduced to the equilibrium problem (EP), and the set of its solutions is denoted by

$$
\operatorname{EP}(F)=\left\{x^{*} \in C: F\left(x^{*}, y\right) \geq 0, \forall y \in C\right\} .
$$

(iv) If $F=0$, then the problem (1.2) is reduced to the mixed variational inequality of Browder type (VI), and the set of its solutions is denoted by

$$
\mathrm{VI}(C, A, \psi)=\left\{x^{*} \in C:\left\langle A x^{*}, y-x^{*}\right\rangle+\psi(y)-\psi\left(x^{*}\right) \geq 0, \forall y \in C\right\}
$$

These show that the problem (1.2) is very general in the sense that numerous problems in physics, optimization, and economics reduce to finding a solution of (1.2). Recently, some methods have been proposed for the generalized mixed equilibrium problem in Banach space (see, e.g., [1-5]).

A Banach space $E$ is said to be strictly convex if $\|x+y\| / 2<1$ for all $x, y \in U=\{z \in E$ : $\|z\|=1\}$ with $x \neq y$. $E$ is said to be uniformly convex if, for each $\epsilon \in(0,2]$, there exists $\delta>0$ such that $\|x+y\| / 2<1-\delta$ for all $x, y \in U$ with $\|x-y\| \geq \epsilon$. E is said to be smooth if the limit

$$
\lim _{t \rightarrow 0} \frac{\|x+t y\|-\|x\|}{t}
$$


exists for all $x, y \in U$. $E$ is said to be uniformly smooth if the above limit exists uniformly in $x, y \in U$.

Remark 1.1. The following basic properties for Banach space $E$ and for the normalized duality mapping $J$ can be found in Cioranescu [6].

(i) If $E$ is an arbitrary Banach space, then $J$ is monotone and bounded;

(ii) If $E$ is a strictly convex Banach space, then $J$ is strictly monotone;

(iii) If $E$ is a a smooth Banach space, then $J$ is single-valued, and hemicontinuous; that is, $J$ is continuous from the strong topology of $E$ to the weak star topology of $E^{*}$;

(iv) If $E$ is a uniformly smooth Banach space, then $J$ is uniformly continuous on each bounded subset of $E$;

(v) If $E$ is a reflexive and strictly convex Banach space with a strictly convex dual $E^{*}$ and $J^{*}: E^{*} \rightarrow E$ is the normalized duality mapping in $E^{*}$, then $J^{-1}=J^{*}, J J^{*}=I_{E^{*}}$ and $J^{*} J=I_{E}$;

(vi) If $E$ is a smooth, strictly convex and reflexive Banach space, then the normalized duality mapping $J$ is single valued, one to one and onto;

(vii) A Banach space $E$ is uniformly smooth if and only if $E^{*}$ is uniformly convex. If $E$ is uniformly smooth, then it is smooth and reflexive.

Recall that a Banach space $E$ has the Kadec-Klee property, if for any sequence $\left\{x_{n}\right\} \subset E$ and $x \in E$ with $x_{n} \rightarrow x \in E$ and $\left\|x_{n}\right\| \rightarrow\|x\|$, then $x_{n} \rightarrow x$ (as $n \rightarrow \infty$ ). It is well known that if $E$ is a uniformly convex Banach space, then $E$ has the Kadec-Klee property.

Next we assume that $E$ is a smooth, strictly convex and reflexive Banach space and $C$ is a nonempty closed convex subset of $E$. In the sequel, we always use $\phi: E \times E \rightarrow \mathbb{R}^{+}$to denote the Lyapunov functional defined by

$$
\phi(x, y)=\|x\|^{2}-2\langle x, J y\rangle+\|y\|^{2}, \quad \forall x, y \in E .
$$

It is obvious from the definition of $\phi$ that

$$
(\|x\|-\|y\|)^{2} \leq \phi(x, y) \leq(\|x\|+\|y\|)^{2}, \quad \forall x, y \in E .
$$

Following Alber [7], the generalized projection $\Pi_{C}: E \rightarrow C$ is defined by

$$
\Pi_{C}(x)=\arg \inf _{y \in C} \phi(y, x), \quad \forall x \in E .
$$

Let $T: C \rightarrow C$ be a mapping and $F(T)$ be the set of fixed points of $T$.

Recall that a point $p \in C$ is said to be an asymptotic fixed point of $T$ if there exists a sequence $\left\{x_{n}\right\} \subset C$ such that $x_{n} \rightarrow p$ and $\left\|x_{n}-T x_{n}\right\| \rightarrow 0$. We denoted the set of all asymptotic fixed points of $T$ by $\widetilde{F}(T)$. A point $p \in C$ is said to be a strong asymptotic fixed point of $T$, if there exists a sequence $\left\{x_{n}\right\} \subset C$ such that $x_{n} \rightarrow p$ and $\left\|x_{n}-T x_{n}\right\| \rightarrow 0$. We denoted the set of all strong asymptotic fixed points of $T$ by $\widehat{F}(T)$. 
Definition 1.2. (1) A mapping $T: C \rightarrow C$ is said to be nonexpansive if

$$
\|T x-T y\| \leq\|x-y\|, \quad \forall x, y \in C .
$$

$\widetilde{F}(T)$ and

(2) A mapping $T: C \rightarrow C$ is said to be relatively nonexpansive [8] if $F(T) \neq \emptyset, F(T)=$

$$
\phi(p, T x) \leq \phi(p, x), \quad \forall x \in C, p \in F(T) .
$$

(3) A mapping $T: C \rightarrow C$ is said to be weak relatively nonexpansive [9] if $F(T) \neq \emptyset$, $F(T)=\widehat{F}(T)$ and

$$
\phi(p, T x) \leq \phi(p, x), \quad \forall x \in C, p \in F(T) .
$$

(4) A mapping $T: C \rightarrow C$ is said to be closed, if for any sequence $\left\{x_{n}\right\} \subset C$ with $x_{n} \rightarrow x$ and $T x_{n} \rightarrow y$, then $T x=y$.

Definition 1.3. (1) A mapping $T: C \rightarrow C$ is said to be quasi- $\phi$-nonexpansive [10] if $F(T) \neq \emptyset$ and

$$
\phi(p, T x) \leq \phi(p, x), \quad \forall x \in C, p \in F(T) .
$$

(2) A mapping $T: C \rightarrow C$ is said to be quasi- $\phi$-asymptotically nonexpansive [11], if $F(T) \neq \emptyset$ and there exists a real sequence $\left\{k_{n}\right\} \subset[1, \infty)$ with $k_{n} \rightarrow 1$ such that

$$
\phi\left(p, T^{n} x\right) \leq k_{n} \phi(p, x), \quad \forall n \geq 1, x \in C, p \in F(T) .
$$

(3) A mapping $T: C \rightarrow C$ is said to be uniformly L-Lipschitz continuous, if there exists a constant $L>0$ such that

$$
\left\|T^{n} x-T^{n} y\right\| \leq L\|x-y\|, \quad \forall x, y \in C, \forall n \geq 1 .
$$

Definition 1.4. (1) A mapping $T: C \rightarrow C$ is said to be total quasi- $\phi$-asymptotically nonexpansive if $F(T) \neq \emptyset$ and there exist nonnegative real sequences $\left\{v_{n}\right\},\left\{\mu_{n}\right\}$ with $v_{n} \rightarrow 0, \mu_{n} \rightarrow 0$ (as $n \rightarrow \infty)$ and a strictly increasing continuous function $\zeta: \mathbb{R}^{+} \rightarrow \mathbb{R}^{+}$with $\zeta(0)=0$ such that for all $x \in C, P \in F(T)$

$$
\phi\left(p, T^{n} x\right) \leq \phi(p, x)+v_{n} \zeta(\phi(p, x))+\mu_{n}, \quad \forall n \geq 1 .
$$

(2) A countable family of mappings $\left\{T_{n}\right\}: C \rightarrow C$ is said to be uniformly total quasi$\phi$-asymptotically nonexpansive, if $\bigcap_{i=1}^{\infty} F\left(T_{i}\right) \neq \emptyset$ and there exist nonnegative real sequences $\left\{v_{n}\right\},\left\{\mu_{n}\right\}$ with $v_{n} \rightarrow 0, \mu_{n} \rightarrow 0$ (as $n \rightarrow \infty$ ) and a strictly increasing continuous function $\zeta: \mathbb{R}^{+} \rightarrow \mathbb{R}^{+}$with $\zeta(0)=0$ such that for all $x \in C, p \in \bigcap_{i=1}^{\infty} F\left(T_{i}\right)$

$$
\phi\left(p, T_{i}^{n} x\right) \leq \phi(p, x)+v_{n} \zeta(\phi(p, x))+\mu_{n}, \quad \forall n \geq 1 .
$$


Remark 1.5. From the definition, it is easy to know that

(1) each relatively nonexpansive mapping is closed;

(2) taking $\zeta(t)=t, t \geq 0, v_{n}=\left(k_{n}-1\right)$ and $\mu_{n}=0$, then (1.16) can be rewritten as

$$
\phi\left(p, T_{i}^{n} x\right) \leq \phi(p, x)+v_{n} \zeta(\phi(p, x))+\mu_{n}, \quad \forall n \geq 1, x \in C, p \in F(T) .
$$

This implies that each quasi- $\phi$-asymptotically nonexpansive mapping must be a total quasi- $\phi$-asymptotically nonexpansive mapping, but the converse is not true;

(3) the class of quasi- $\phi$-asymptotically nonexpansive mappings contains properly the class of quasi- $\phi$-nonexpansive mappings as a subclass, but the converse is not true;

(4) the class of quasi- $\phi$-nonexpansive mappings contains properly the class of weak relatively nonexpansive mappings as a subclass, but the converse is not true;

(5) the class of weak relatively nonexpansive mappings contains properly the class of relatively nonexpansive mappings as a subclass, but the converse is not true. such that

A mapping $A: C \rightarrow E^{*}$ is said to be $\alpha$-inverse strongly monotone, if there exists $\alpha>0$

$$
\langle x-y, A x-A y\rangle \geq \alpha\|A x-A y\|^{2}
$$

Remark 1.6. If $A$ is an $\alpha$-inverse strongly monotone mapping, then it is $1 / \alpha$-Lipschitz continuous.

Iterative approximation of fixed points for relatively nonexpansive mappings in the setting of Banach spaces has been studied extensively by many authors. In 2005, Matsushita and Takahashi [12] obtained some weak and strong convergence theorems to approximate a fixed point of a single relatively nonexpansive mapping. Recently, Ofoedu and Malonza [4], Zhang [5], Su et al. [13], Zegeye and Shahzad [14], Wattanawitoon and Kumam [15], Qin et al. [16], Takahashi and Zembayashi [17], Chang et al. [18, 19], Yao et al. [20, 21], Qin et al. [22], and Cho et al. [23, 24] extend the notions from relatively nonexpansive mappings, weakly relatively nonexpansive mappings or quasi- $\phi$-nonexpansive mappings to quasi- $\phi$-asymptotically nonexpansive mappings and also prove some strongence theorems to approximate a common fixed point of quasi- $\phi$-nonexpansive mappings or quasi- $\phi$ asymptotically nonexpansive mappings.

The purpose of this paper is first to introduce the concept of total quasi- $\phi$-asymptotically nonexpansive mapping which contains many kinds of mappings as its special cases, and then by using a hybrid algorithm to introduce a new iterative scheme for finding a common element of the set of solutions for a system of generalized mixed equilibrium problems and the set of common fixed points for a countable family of total quasi- $\phi$-asymptotically nonexpansive mappings in a uniformly smooth and strictly convex Banach space with KadecKlee property. The results improve and extend the corresponding results in [8, 11-25].

\section{Preliminaries}

First, we recall some definitions and conclusions. 
Lemma 2.1 (see $[7,26]$ ). Let $E$ be a smooth, strictly convex and reflexive Banach space and C be a nonempty closed convex subset of $E$. Then the following conclusions hold:

(a) $\phi\left(x, \Pi_{C} y\right)+\phi\left(\Pi_{C} y, y\right) \leq \phi(x, y)$ for all $x \in C$ and $y \in E$;

(b) if $x \in E$ and $z \in C$, then

$$
z=\Pi_{C} x \Longleftrightarrow\langle z-y, J x-J z\rangle \geq 0, \quad \forall y \in C ;
$$

(c) for $x, y \in E, \phi(x, y)=0$ if and only if $x=y$.

Remark 2.2. If $E$ is a real Hilbert space $H$, then $\phi(x, y)=\|x-y\|^{2}$ and $\Pi_{C}$ is the metric projection $P_{C}$ of $H$ onto $C$.

Lemma 2.3 (see [18]). Let $E$ be a uniformly convex Banach space, $r>0$ a positive number, and $B_{r}(0)$ a closed ball of $E$. Then, for any given sequence $\left\{x_{i}\right\}_{i=1}^{\infty} \subset B_{r}(0)$ and for any given sequence $\left\{\lambda_{i}\right\}_{i=1}^{\infty}$ of positive numbers with $\sum_{i=1}^{\infty} \lambda_{i}=1$, then there exists a continuous, strictly increasing and convex function $g:[0,2 r) \rightarrow[0, \infty)$ with $g(0)=0$ such that for any positive integers $i, j$ with $i<j$,

$$
\left\|\sum_{n=1}^{\infty} \lambda_{n} x_{n}\right\|^{2} \leq \sum_{n=1}^{\infty} \lambda_{n}\left\|x_{n}\right\|^{2}-\lambda_{i} \lambda_{j} g\left(\left\|x_{i}-x_{j}\right\|\right) .
$$

Lemma 2.4. Let $E$ be a real uniformly smooth and strictly convex Banach space with Kadec-Klee property, and let $C$ be a nonempty closed convex subset of $E$. Let $T: C \rightarrow C$ be a closed and total quasi$\phi$-asymptotically nonexpansive mapping with nonnegative real sequences $\left\{v_{n}\right\},\left\{\mu_{n}\right\}$ and a strictly increasing continuous functions $\zeta: \mathbb{R}^{+} \rightarrow \mathbb{R}^{+}$such that $\mu_{1}=0, v_{n} \rightarrow 0, \mu_{n} \rightarrow 0$ (as $n \rightarrow \infty$ ) and $\zeta(0)=0$. Then $F(T)$ is a closed convex subset of $C$.

Proof. Letting $\left\{p_{n}\right\}$ be a sequence in $F(T)$ with $p_{n} \rightarrow p$ (as $\left.n \rightarrow \infty\right)$, we prove that $p \in F(T)$. In fact, from the definition of $T$, we have

$$
\phi\left(p_{n}, T p\right) \leq \phi\left(p_{n}, p\right)+v_{1} \zeta\left(\phi\left(p_{n}, p\right)\right)+\mu_{1} \longrightarrow 0 \quad(\text { as } n \longrightarrow \infty)
$$

Therefore we have

$$
\begin{aligned}
\lim _{n \rightarrow \infty} \phi\left(p_{n}, T p\right) & =\lim _{n \rightarrow \infty}\left(\left\|p_{n}\right\|^{2}-2\left\langle p_{n}, J T p\right\rangle\right)+\|T p\|^{2} \\
& =\|p\|^{2}-2\langle p, J T p\rangle+\|T p\|^{2}=\phi(p, T p)=0,
\end{aligned}
$$

that is, $p \in F(T)$.

Next we prove that $F(T)$ is convex. For any $p, q \in F(T), t \in(0,1)$, putting $w=t p+(1-$ t) $q$, we prove that $w \in F(T)$. Indeed, in view of the definition of $\phi(x, y)$, we have

$$
\begin{aligned}
\phi\left(w, T^{n} w\right) & =\|w\|^{2}-2\left\langle w, J T^{n} w\right\rangle+\left\|T^{n} w\right\|^{2} \\
& =\|w\|^{2}-2 t\left\langle p, J T^{n} w\right\rangle-2(1-t)\left\langle q, J T^{n} w\right\rangle+\left\|T^{n} w\right\|^{2}
\end{aligned}
$$


Journal of Applied Mathematics

$$
\begin{aligned}
= & \|w\|^{2}+t \phi\left(p, T^{n} w\right)+(1-t) \phi\left(q, T^{n} w\right)-t\|p\|^{2}-(1-t)\|q\|^{2} \\
\leq & \|w\|^{2}+t\left(\phi(p, w)+v_{n} \zeta(\phi(p, w))+\mu_{n}\right)+(1-t)\left(\phi(q, w)+v_{n} \zeta(\phi(q, w))+\mu_{n}\right) \\
& -t\|p\|^{2}-(1-t)\|q\|^{2} \\
= & \|w\|^{2}+t\left(\|p\|^{2}-2\langle p, J w\rangle+\|w\|^{2}\right)+t\left(v_{n} \zeta(\phi(p, w))+\mu_{n}\right)+(1-t) \\
& \times\left(\|q\|^{2}-2\langle q, J w\rangle+\|w\|^{2}\right)+(1-t)\left(v_{n} \zeta(\phi(q, w))+\mu_{n}\right)-t\|p\|^{2}-(1-t)\|q\|^{2} \\
= & \|w\|^{2}-2\langle w, J w\rangle+\|w\|^{2}+t v_{n} \zeta(\phi(p, w))+(1-t)\left(v_{n} \zeta(\phi(q, w))+\mu_{n}\right. \\
= & t v_{n} \zeta(\phi(p, w))+(1-t)\left(v_{n} \zeta(\phi(q, w))+\mu_{n} .\right.
\end{aligned}
$$

Since $\mu_{n} \rightarrow 0$ and $v_{n} \rightarrow 0$, we have $\phi\left(w, T^{n} w\right) \rightarrow 0$ (as $n \rightarrow \infty$ ). From (1.10) we have $\left\|T^{n} w\right\| \rightarrow\|w\|$. Consequently $\left\|J T^{n} w\right\| \rightarrow\|J w\|$. This implies that $\left\{J T^{n} w\right\}$ is a bounded sequence. Since $E$ is reflexive, $E^{*}$ is also reflexive. So we can assume that

$$
J T^{n} w \rightarrow f_{0} \in E^{*}
$$

Again since $E$ is reflexive, we have $J(E)=E^{*}$. Therefore there exists $x \in E$ such that $J x=f_{0}$. By virtue of the weakly lower semicontinuity of norm $\|\cdot\|$, we have

$$
\begin{aligned}
0=\liminf _{n \rightarrow \infty} \phi\left(w, T^{n} w\right) & =\liminf _{n \rightarrow \infty}\left(\|w\|^{2}-2\left\langle w, J\left(T^{n} w\right)\right\rangle+\left\|T^{n} w\right\|^{2}\right) \\
& =\liminf _{n \rightarrow \infty}\left(\|w\|^{2}-2\left\langle w, J\left(T^{n} w\right)\right\rangle+\left\|J\left(T^{n} w\right)\right\|^{2}\right) \\
& \geq\|w\|^{2}-2\left\langle w, f_{0}\right\rangle+\left\|f_{0}\right\|^{2} \\
& =\|w\|^{2}-2\langle w, J x\rangle+\|J x\|^{2} \\
& =\|w\|^{2}-2\langle w, J x\rangle+\|x\|^{2}=\phi(w, x),
\end{aligned}
$$

that is, $w=x$ which implies that $f_{0}=J w$. Hence from (2.6) we have $J T^{n} w \rightarrow J w \in E^{*}$. Since $\left\|J T^{n} w\right\| \rightarrow\|w\|$ and $E^{*}$ has the Kadec-Klee property, we have $J T^{n} w \rightarrow J w$. Since $E$ is uniformly smooth, $E^{*}$ is uniformly convex, which in turn implies that $E^{*}$ is smooth. From Remark 1.1(iii) it yields that $J^{-1}: E^{*} \rightarrow E$ is hemi-continuous. Therefore we have $T^{n} w-w$. Again since $\left\|T^{n} w\right\| \rightarrow\|w\|$, by using the Kadec-Klee property of $E$, we have $T^{n} w \rightarrow w$. This implies that $T T^{n} w=T^{n+1} w \rightarrow w$. Since $T$ is closed, we have $w=T w$.

This completes the proof of Lemma 2.4.

Lemma 2.5. Let $E$ be a smooth, strictly convex and reflexive Banach space and $C$ be a nonempty closed convex subset of $E$. Let $f: C \times C \rightarrow \mathbb{R}$ be a bifunction satisfying the following conditions:

(A1) $f(x, x)=0$, for all $x \in C$,

(A2) $f$ is monotone, that is, $f(x, y)+f(y, x) \leq 0$, for all $x, y \in C$, 
(A3) $\lim \sup _{t \downarrow 0} f(x+t(z-x), y) \leq f(x, y)$ for all $x, z, y \in C$,

(A4) The function $y \mapsto f(x, y)$ is convex and lower semi-continuous.

Then the following conclusions hold:

(1) (Blum and Oettli [27]) for any given $r>0$ and $x \in E$, there exists a unique $z \in C$ such that

$$
f(z, y)+\frac{1}{r}\langle y-z, J z-J x\rangle \geq 0, \quad \forall y \in C
$$

(2) (Takahashi and Zembayashi [28]) for any given $r>0$ and $x \in E$, define a mapping $K_{r}^{f}$ : $E \rightarrow C$ by

$$
K_{r}^{f}(x)=\left\{z \in C: f(z, y)+\frac{1}{r}\langle y-z, J z-J x\rangle \geq 0, \forall y \in C\right\}, \quad x \in E .
$$

Then, the following conclusions hold:

(a) $K_{r}^{f}$ is single-valued;

(b) $K_{r}^{f}$ is firmly nonexpansive-type mapping, that is, for all $z, y \in E$,

$$
\left\langle K_{r}^{f} z-K_{r}^{f} y, J K_{r}^{f} z-J K_{r}^{f} y\right\rangle \leq\left\langle K_{r}^{f} z-K_{r}^{f} y, J z-J y\right\rangle
$$

(c) $F\left(K_{r}^{f}\right)=\mathrm{EP}(f)$ and $K_{r}^{f}$ is quasi- $\phi$-nonexpansive;

(d) $\mathrm{EP}(f)$ is closed and convex;

(e) $\phi\left(q, K_{r}^{f} x\right)+\phi\left(K_{r}^{f} x, x\right) \leq \phi(q, x)$, for all $q \in F\left(K_{r}^{f}\right)$.

For solving the generalized mixed equilibrium problem (1.2), let us assume that the following conditions are satisfied:

(1) $E$ is a smooth, strictly convex, and reflexive Banach space and $C$ is a nonempty closed convex subset of $E$;

(2) $A: C \rightarrow E^{*}$ is $\beta$-inverse strongly monotone mapping;

(3) $F: C \times C \rightarrow \mathbb{R}$ is bifunction satisfying the conditions (A1), (A3), (A4) in Lemma 2.5 and the following condition $(A 2)^{\prime}$ :

$(A 2)^{\prime}$ for some $\gamma \geq 0$ with $\gamma \leq \beta$

$$
F(x, y)+F(y, x) \leq r\|A x-A y\|^{2}, \quad \forall x, y \in C ;
$$

(4) $\psi: C \rightarrow \mathbb{R}$ is a lower semicontinuous and convex function.

Under the assumptions as above, we have the following results. 
Lemma 2.6. Let $E, C, A, F, \psi$ satisfy the above conditions (1)-(4). Denote by

$$
\Gamma(x, y)=F(x, y)+\psi(y)-\psi(x)+\langle A x, y-x\rangle, \quad \forall x, y \in C .
$$

For any given $r>0$ and $x \in E$, define a mapping $K_{r}^{\Gamma}: E \rightarrow C$ by

$$
K_{r}^{\Gamma}(x)=\left\{z \in C: \Gamma(z, y)+\frac{1}{r}\langle y-z, J z-J x\rangle \geq 0, \forall y \in C\right\} .
$$

Then, the following hold:

(a) $K_{r}^{\Gamma}$ is single-valued;

(b) $K_{r}^{\Gamma}$ is a firmly nonexpansive-type mapping, that is, for all $z, y \in E$,

$$
\left\langle K_{r}^{\Gamma}(z)-K_{r}^{\Gamma}(y), J K_{r}^{\Gamma}(z)-J K_{r}^{\Gamma}(y)\right\rangle \leq\left\langle K_{r}^{\Gamma}(z)-K_{r}^{\Gamma}(y), J z-J y\right\rangle ;
$$

(c) $F\left(K_{r}^{\Gamma}\right)=\mathrm{EP}(\Gamma)=\operatorname{GMEP}(F, A, \psi)$;

(d) $\operatorname{GMEP}(F, A, \psi)$ is closed and convex;

(e)

$$
\phi\left(q, K_{r}^{\Gamma} x\right)+\phi\left(K_{r}^{\Gamma} x, x\right) \leq \phi(q, x), \quad \forall q \in F\left(K_{r}^{\Gamma}\right)
$$

Proof. It follows from Lemma 2.5 that in order to prove the conclusions of Lemma 2.6 it is sufficient to prove that the function $\Gamma: C \times C \rightarrow \mathbb{R}$ satisfies the conditions $(A 1)-(A 4)$ in Lemma 2.5.

In fact, by the similar method as given in the proof of Lemma 2.4 in [1], we can prove that the function $\Gamma$ satisfies the conditions $(A 1),(A 3)$, and $(A 4)$. Now we prove that $\Gamma$ also satisfies the conditions $(A 2)$.

Indeed, for any $x, y \in C$, by condition $(A 2)^{\prime}$, we have

$$
\begin{aligned}
\Gamma(x, y)+\Gamma(y, x)= & F(x, y)+\psi(y)-\psi(x)+\langle A x, y-x\rangle \\
& +F(y, x)+\psi(x)-\psi(y)+\langle A y, x-y\rangle \\
= & F(x, y)+F(y, x)-\langle A x-A y, x-y\rangle \\
\leq & (\gamma-\beta)\|A x-A y\|^{2} \leq 0 .
\end{aligned}
$$

This implies that the function $\Gamma$ satisfies the conditions $(A 2)$. Therefore the conclusions of Lemma 2.6 can be obtained from Lemma 2.3 immediately.

Remark 2.7. It follows from Lemma 2.5 that the mapping $K_{r}^{\Gamma}$ is a relatively nonexpansive mapping. Thus, it is quasi- $\phi$-nonexpansive. 


\section{Main Results}

In this section, we shall use the hybrid method to prove some strong convergence theorems for finding a common element of the set of solutions for a system of the generalized mixed equilibrium problems (1.2) and the set of common fixed points of a countable family of total quasi- $\phi$-asymptotically nonexpansive mappings in Banach spaces. conditions.

In the sequel, we assume that $E, C,\left\{S_{i}\right\}_{i=1}^{\infty},\left\{A_{i}\right\}_{i=1}^{M},\left\{F_{i}\right\}_{i=1}^{M},\left\{\psi_{i}\right\}_{i=1}^{M}$ satisfy the following

(1) Let $E$ be a uniformly smooth and strictly convex Banach space with Kleac-Klee property and $C$ a nonempty closed convex subset of $E$.

(2) Let $S_{i}: C \rightarrow C$ be a countable family of closed and uniformly total quasi- $\phi$ asymptotically nonexpansive mappings with nonnegative real sequences $\left\{v_{n}\right\},\left\{\mu_{n}\right\}$ and a strictly increasing continuous functions $\zeta: \mathbb{R}^{+} \rightarrow \mathbb{R}^{+}$such that $v_{n} \rightarrow 0, \mu_{n} \rightarrow$ 0 (as $n \rightarrow \infty$ ) and $\mu_{1}=0, \zeta(0)=0$. Suppose further that for each $i \geq 1, S_{i}$ is a uniformly $L_{i}$-Lipschitz mapping, that is, there exists a constant $L_{i}>0$ such that

$$
\left\|S_{i}^{n} x-S_{i}^{n} y\right\| \leq L_{i}\|x-y\|, \quad \forall x, y \in C, \forall n \geq 1 .
$$

(3) Let $A_{i}: C \rightarrow E^{*}(i=1,2, \ldots, M)$ be a finite family of $\beta_{i}$-inverse strongly monotone mappings.

(4) Let $F_{i}: C \rightarrow \mathbb{R}(i=1,2, \ldots, M)$ be a finite family of bifunction satisfying the conditions $(A 1),(A 3),(A 4)$, and the following condition $(A 2)^{\prime}$ :

$(A 2)^{\prime}$ For each $i=1,2, \ldots, M$ there exists $\gamma_{i} \geq 0$ with $\gamma_{i} \leq \beta_{i}$ such that

$$
F_{i}(x, y)+F_{i}(y, x) \leq \gamma_{i}\left\|A_{i} x-A_{i} y\right\|^{2}, \quad \forall x, y \in C ;
$$

(5) Let $\psi_{i}: C \rightarrow \mathbb{R}(i=1,2, \ldots, M)$ be a finite family of lower semicontinuous and convex functions.

Theorem 3.1. Let $E, C,\left\{S_{i}\right\}_{i=1}^{\infty},\left\{A_{i}\right\}_{i=1}^{M},\left\{F_{i}\right\}_{i=1}^{M},\left\{\psi_{i}\right\}_{i=1}^{M}$ be the same as above. Suppose that

$$
\mathcal{F}:=\bigcap_{i=1}^{\infty} F\left(T_{i}\right) \bigcap_{j=1}^{M} \operatorname{GMEP}\left(F_{j}, A_{j}, \psi_{j}\right)
$$

is a nonempty and bounded subset of $C$. For any given $x_{0} \in C$, let $\left\{x_{n}\right\}$ be the sequence generated by

$$
\begin{aligned}
& x_{0} \in C_{0}=C, \\
& z_{n}=J^{-1}\left(\alpha_{n, 0} J x_{n}+\sum_{i=1}^{\infty} \alpha_{n, i} J S_{i}^{n} x_{n}\right),
\end{aligned}
$$


Journal of Applied Mathematics

$$
\begin{aligned}
& y_{n}=J^{-1}\left(\alpha_{n} J z_{n}+\left(1-\alpha_{n}\right) J x_{n}\right), \\
& u_{n}=K_{r_{M, n}}^{\Gamma_{M}} K_{r_{M-1, n}}^{\Gamma_{M-1}} \cdots K_{r_{2, n}}^{\Gamma_{2}} K_{r_{1, n}}^{\Gamma_{1}} y_{n}, \\
& C_{n+1}=\left\{v \in C_{n}: \phi\left(v, u_{n}\right) \leq \phi\left(v, x_{n}\right)+\eta_{n}\right\}, \\
& x_{n+1}=\prod_{C_{n+1}} x_{0}, \quad \forall n \geq 0,
\end{aligned}
$$

where

$$
\eta_{n}=v_{n} \sup _{u \in \mathscr{F}} \zeta\left(\phi\left(u, x_{n}\right)\right)+\mu_{n}, \quad \forall n \geq 1
$$

$K_{r_{i, n}}^{\Gamma_{i}}: E \rightarrow C, i=1,2, \ldots, M$ is the mapping defined by (2.13) with $\Gamma=\Gamma_{i}, r=r_{i, n}$, and

$$
\Gamma_{i}(x, y)=F_{i}(x, y)+\left\langle A_{i} x, y-x\right\rangle+\psi_{i}(y)-\psi_{i}(x), \quad \forall x, y \in C
$$

$r_{k, n} \in[d, \infty), k=1,2, \ldots, M, n \geq 1$ for some $d>0, \Pi_{C_{n+1}}$ is the generalized projection of $E$ onto the set $C_{n+1}$, and $\left\{\alpha_{n, i}\right\},\left\{\alpha_{n}\right\}$ are sequences in $[0,1]$ satisfying the following conditions:

(a) $\sum_{i=0}^{\infty} \alpha_{n, i}=1$ for all $n \geq 0$;

(b) $\liminf _{n \rightarrow \infty} \alpha_{n, 0} \cdot \alpha_{n, i}>0$ for all $i \geq 1$;

(c) $0<\alpha \leq \alpha_{n}<1$ for some $\alpha \in(0,1)$.

Then $\left\{x_{n}\right\}$ converges strongly to $\Pi_{\mp} x_{0}$, where $\Pi_{\mp}$ is the generalized projection from $E$ onto $\mathcal{F}$.

Proof. We divide the proof of Theorem 3.1 into five steps.

(i) We first prove that $\mp$ and $C_{n}$ both are closed and convex subset of $C$ for all $n \geq 0$.

In fact, it follows from Lemmas 2.4 and 2.6 that $F\left(S_{i}\right), i \geq 1$ and $\operatorname{GMEP}\left(F_{j}, A_{j}, \psi_{j}\right)(j=$ $1,2, \ldots, M)$ both are closed and convex. Therefore $F$ is a closed and convex subset in $C$. Furthermore, it is obvious that $C_{0}=C$ is closed and convex. Suppose that $C_{n}$ is closed and convex for some $n \geq 1$. Since the inequality $\phi\left(v, u_{n}\right) \leq \phi\left(v, x_{n}\right)+\eta_{n}$ is equivalent to

$$
2\left\langle v, J x_{n}-J u_{n}\right\rangle \leq\left\|x_{n}\right\|^{2}-\left\|u_{n}\right\|^{2}+\eta_{n}
$$

therefore, we have

$$
C_{n+1}=\left\{v \in C_{n}: 2\left\langle v, J x_{n}-J u_{n}\right\rangle \leq\left\|x_{n}\right\|^{2}-\left\|u_{n}\right\|^{2}+\eta_{n}\right\} .
$$

This implies that $C_{n+1}$ is closed and convex. The desired conclusions are proved. These in turn show that $\Pi_{\mp} x_{0}$ and $\Pi_{C_{n}} x_{0}$ are well defined.

(ii) We prove that $\left\{x_{n}\right\}$ and $\left\{S_{i}^{n} x_{n}\right\}_{n=0}^{\infty}$ for all $i \geq 1$ are both bounded sequences in $C$. 
By the definition of $C_{n}$, we have $x_{n}=\Pi_{C_{n}} x_{0}$ for all $n \geq 0$. It follows from Lemma 2.1 (a) that

$$
\begin{aligned}
\phi\left(x_{n}, x_{0}\right) & =\phi\left(\Pi_{C_{n}} x_{0}, x_{0}\right) \leq \phi\left(u, x_{0}\right)-\phi\left(u, \Pi_{C_{n}} x_{0}\right) \\
& \leq \phi\left(u, x_{0}\right), \quad \forall n \geq 0, u \in \mathcal{F} .
\end{aligned}
$$

This implies that $\left\{\phi\left(x_{n}, x_{0}\right)\right\}$ is bounded. By virtue of (1.10), $\left\{x_{n}\right\}$ is bounded. Since $\phi\left(u, S_{i}^{n} x_{n}\right) \leq \phi\left(u, x_{n}\right)+v_{n} \zeta\left(\phi\left(u, x_{n}\right)\right)+\mu_{n}$ for all $u \in \mathcal{F}$ and $i \geq 1,\left\{S_{i}^{n} x_{n}\right\}$ is bounded for all $i \geq 1$, and so $\left\{z_{n}\right\}$ is bounded in $E$. Denote $M$ by

$$
M=\sup _{n \geq 0, i \geq 1}\left\{\left\|x_{n}\right\|,\left\|S_{i}^{n} x_{n}\right\|,\left\|z_{n}\right\|\right\}<\infty
$$

In view of the structure of $\left\{C_{n}\right\}$, we have $C_{n+1} \subset C_{n}, x_{n}=\Pi_{C_{n}} x_{0}$ and $x_{n+1}=\Pi_{C_{n+1}} x_{0}$. This implies that $x_{n+1} \in C_{n}$ and

$$
\phi\left(x_{n}, x_{0}\right) \leq \phi\left(x_{n+1}, x_{0}\right), \quad \forall n \geq 1
$$

Therefore $\left\{\phi\left(x_{n}, x_{0}\right)\right\}$ is convergent. Without loss of generality, we can assume that

$$
\lim _{n \rightarrow \infty} \phi\left(x_{n}, x_{0}\right)=r \geq 0
$$

(iii) Next, we prove that $\mathcal{F}:=\bigcap_{i=1}^{\infty} F\left(S_{i}\right) \bigcap \bigcap_{i=1}^{M} \operatorname{GMEP}\left(F_{i}, A_{i}, \psi_{i}\right) \subset C_{n}$ for all $n \geq 0$.

Indeed, it is obvious that $\mathscr{F} \subset C_{0}=C$. Suppose that $\mathscr{F} \subset C_{n}$ for some $n \geq 0$. Since $u_{n}=K_{r_{M, n}}^{\Gamma_{M}} K_{r_{M-1, n}}^{\Gamma_{M-1}} \cdots K_{r_{2, n}}^{\Gamma_{2}} K_{r_{1, n}}^{\Gamma_{1}} y_{n}$, by Lemma 2.6 and Remark 2.7, $K_{r_{i, n}}^{\Gamma_{i}}$ is quasi- $\phi$-nonexpansive. Again since $E$ is uniformly smooth, $E^{*}$ is uniformly convex. Hence, For any given $u \in \mathcal{F} \subset C_{n}$ and for any positive integer $j>0$, from Lemma 2.3 we have

$$
\begin{aligned}
\phi\left(u, u_{n}\right) & =\phi\left(u, K_{r_{M, n}}^{\Gamma_{M}} K_{r_{M-1, n}}^{\Gamma_{M-1}} \cdots K_{r_{2, n}}^{\Gamma_{2}} K_{r_{1, n}}^{\Gamma_{1}} y_{n}\right) \leq \phi\left(u, y_{n}\right) \\
& =\phi\left(u, J^{-1}\left(\alpha_{n} J z_{n}+\left(1-\alpha_{n}\right) J x_{n}\right)\right) \\
& \leq\|u\|^{2}-2\left\langle u, \alpha_{n} J z_{n}+\left(1-\alpha_{n}\right) J x_{n}\right\rangle+\left\|\alpha_{n} J z_{n}+\left(1-\alpha_{n}\right) J x_{n}\right\|^{2} \\
& \leq\|u\|^{2}-2\left\langle u, \alpha_{n} J z_{n}+\left(1-\alpha_{n}\right) J x_{n}\right\rangle+\alpha_{n}\left\|J z_{n}\right\|^{2}+\left(1-\alpha_{n}\right)\left\|J x_{n}\right\|^{2} \\
& =\|u\|^{2}-2\left\langle u, \alpha_{n} J z_{n}+\left(1-\alpha_{n}\right) J x_{n}\right\rangle+\alpha_{n}\left\|z_{n}\right\|^{2}+\left(1-\alpha_{n}\right)\left\|x_{n}\right\|^{2} \\
& =\alpha_{n} \phi\left(u, z_{n}\right)+\left(1-\alpha_{n}\right) \phi\left(u, x_{n}\right) \\
& =\alpha_{n} \phi\left(u, J^{-1}\left(\alpha_{n, 0} J x_{n}+\sum_{i=1}^{\infty} \alpha_{n, i} J S_{i}^{n} x_{n}\right)\right)+\left(1-\alpha_{n}\right) \phi\left(u, x_{n}\right)
\end{aligned}
$$


Journal of Applied Mathematics

$$
\begin{aligned}
= & \alpha_{n}\left(\|u\|^{2}-2 \alpha_{n, 0}\left\langle u, J x_{n}\right\rangle-2 \sum_{i=1}^{\infty} \alpha_{n, i}\left\langle u, J S_{i}^{n} x_{n}\right\rangle+\left\|\alpha_{n, 0} J x_{n}+\sum_{i=1}^{\infty} \alpha_{n, i} J S_{i}^{n} x_{n}\right\|^{2}\right) \\
& +\left(1-\alpha_{n}\right) \phi\left(u, x_{n}\right) \\
\leq & \alpha_{n}\left(\|u\|^{2}-2 \alpha_{n, 0}\left\langle u, J x_{n}\right\rangle-2 \sum_{i=1}^{\infty} \alpha_{n, i}\left\langle u, J S_{i}^{n} x_{n}\right\rangle+\alpha_{n, 0}\left\|J x_{n}\right\|^{2}+\sum_{i=1}^{\infty} \alpha_{n, i}\left\|J S_{i}^{n} x_{n}\right\|^{2}\right. \\
& \left.\quad-\alpha_{n, 0} \alpha_{n, j} g\left(\left\|J x_{n}-J S_{j}^{n} x_{n}\right\|\right)\right)+\left(1-\alpha_{n}\right) \phi\left(u, x_{n}\right) \\
\leq & \alpha_{n}\left(\|u\|^{2}-2 \alpha_{n, 0}\left\langle u, J x_{n}\right\rangle-2 \sum_{i=1}^{\infty} \alpha_{n, i}\left\langle u, J S_{i}^{n} x_{n}\right\rangle+\alpha_{n, 0}\left\|x_{n}\right\|^{2}+\sum_{i=1}^{\infty} \alpha_{n, i}\left\|S_{i}^{n} x_{n}\right\|^{2}\right. \\
& \left.\quad-\alpha_{n, 0} \alpha_{n, j} g\left(\left\|J x_{n}-J S_{j}^{n} x_{n}\right\|\right)\right)+\left(1-\alpha_{n}\right) \phi\left(u, x_{n}\right) \\
= & \alpha_{n}\left(\alpha_{n, 0} \phi\left(u, x_{n}\right)+\sum_{i=1}^{\infty} \alpha_{n, i} \phi\left(u, S_{i}^{n} x_{n}\right)-\alpha_{n, 0} \alpha_{n, j} g\left(\left\|J x_{n}-J S_{j}^{n} x_{n}\right\|\right)\right) \\
& +\left(1-\alpha_{n}\right) \phi\left(u, x_{n}\right) \\
\leq & \phi\left(u, x_{n}\right)+\eta_{n} . \\
\leq & \alpha_{n}\left(\phi\left(u, x_{n}\right)+\sum_{i=1}^{\infty} \alpha_{n, i}\left(v_{n} \zeta\left(\phi\left(u, x_{n}\right)\right)+\mu_{n}\right)-\alpha_{n, 0} \alpha_{n, j} g\left(\left\|J x_{n}-J S_{j}^{n} x_{n}\right\|\right)\right) \\
\leq & \alpha_{n}\left(\alpha_{n, 0} \phi\left(u, x_{n}\right)+\sum_{i=1}^{\infty} \alpha_{n, i}\left\{\phi\left(u, x_{n}\right)+v_{n} \zeta\left(\phi\left(u, x_{n}\right)\right)+\mu_{n}\right\}\right. \\
&
\end{aligned}
$$

Hence $u \in C_{n+1}$ and so $\mp \subset C_{n}$ for all $n \geq 0$. By the way, from the definition of $\left\{\eta_{n}\right\}$ and $\zeta$ and (3.10), it is easy to see that

$$
\eta_{n}=v_{n} \sup _{u \in \mathscr{F}} \zeta\left(\phi\left(u, x_{n}\right)\right)+\mu_{n} \leq v_{n} \sup _{u \in \mathscr{F}} \zeta\left((\|u\|+M)^{2}\right)+\mu_{n} \longrightarrow 0 \quad(\text { as } n \longrightarrow \infty) .
$$


(IV) Now, we prove that $\left\{x_{n}\right\}$ converges strongly to some point

$$
p \in \mathcal{F}:=\bigcap_{i=1}^{\infty} F\left(S_{i}\right) \bigcap \bigcap_{j=1}^{\infty} \operatorname{GMEP}\left(F_{j}, A_{j}, \psi_{j}\right) .
$$

First, we prove that $\left\{x_{n}\right\}$ converges strongly to some point $p \in \bigcap_{i=1}^{\infty} F\left(S_{i}\right)$.

In fact, since $\left\{x_{n}\right\}$ is bounded in $C$ and $E$ is reflexive, there exists a subsequence $\left\{x_{n_{i}}\right\} \subset$ $\left\{x_{n}\right\}$ such that $x_{n_{i}} \rightarrow p$. Again since $C_{n}$ is closed and convex for each $n \geq 1$, it is weakly closed, and so $p \in C_{n}$ for each $n \geq 0$. Since $x_{n}=\Pi_{C_{n}} x_{0}$, from the definition of $\Pi_{C_{n}}$, we have

$$
\phi\left(x_{n_{i}}, x_{0}\right) \leq \phi\left(p, x_{0}\right), \quad n \geq 0
$$

Since

$$
\begin{aligned}
\liminf _{n_{i} \rightarrow \infty} \phi\left(x_{n_{i}}, x_{0}\right) & =\liminf _{n_{i} \rightarrow \infty}\left\{\left\|x_{n_{i}}\right\|^{2}-2\left\langle x_{n_{i}}, J x_{0}\right\rangle+\left\|x_{0}\right\|^{2}\right\} \\
& \geq\|p\|^{2}-2\left\langle p, J x_{0}\right\rangle+\left\|x_{0}\right\|^{2}=\phi\left(p, x_{0}\right),
\end{aligned}
$$

we have

$$
\phi\left(p, x_{0}\right) \leq \liminf _{n_{i} \rightarrow \infty} \phi\left(x_{n_{i}}, x_{0}\right) \leq \limsup _{n_{i} \rightarrow \infty} \phi\left(x_{n_{i}}, x_{0}\right) \leq \phi\left(p, x_{0}\right) .
$$

This implies that $\lim _{n_{i} \rightarrow \infty} \phi\left(x_{n_{i}}, x_{0}\right)=\phi\left(p, x_{0}\right)$, that is, $\left\|x_{n_{i}}\right\| \rightarrow\|p\|$. In view of the Kadec-Klee property of $E$, we obtain that $\lim _{n \rightarrow \infty} x_{n_{i}}=p$.

Now we prove that $x_{n} \rightarrow p(n \rightarrow \infty)$. In fact, if there exists a subsequence $\left\{x_{n_{j}}\right\} \subset$ $\left\{x_{n}\right\}$ such that $x_{n_{j}} \rightarrow q$, then we have

$$
\begin{aligned}
\phi(p, q) & =\lim _{n_{i} \rightarrow \infty, n_{j} \rightarrow \infty} \phi\left(x_{n_{i}}, x_{n_{j}}\right) \leq \lim _{n_{i} \rightarrow \infty, n_{j} \rightarrow \infty} \phi\left(x_{n_{i}} x_{0}\right)-\phi\left(\Pi_{C_{n_{j}}} x_{0}, x_{0}\right) \\
& =\lim _{n_{i} \rightarrow \infty, n_{j} \rightarrow \infty} \phi\left(x_{n_{i}}, x_{0}\right)-\phi\left(x_{n_{j}}, x_{0}\right)=0 \quad \text { (by (3.12)). }
\end{aligned}
$$

Therefore we have $p=q$. This implies that

$$
\lim _{n \rightarrow \infty} x_{n}=p
$$

Now we prove that $p \in \bigcap_{i=1}^{\infty} F\left(S_{i}\right)$. In fact, by the construction of $C_{n}$, we have that $C_{n+1} \subset C_{n}$ and $x_{n+1}=\Pi_{C_{n+1}} x_{0}$. Therefore by Lemma 2.1(a) we have

$$
\begin{aligned}
\phi\left(x_{n+1}, x_{n}\right) & =\phi\left(x_{n+1}, \Pi_{C_{n}} x_{0}\right) \\
& \leq \phi\left(x_{n+1}, x_{0}\right)-\phi\left(\Pi_{C_{n}} x_{0}, x_{0}\right) \\
& =\phi\left(x_{n+1}, x_{0}\right)-\phi\left(x_{n}, x_{0}\right) \longrightarrow 0 \quad(\text { as } n \longrightarrow \infty) .
\end{aligned}
$$


In view of $x_{n+1} \in C_{n}$ and noting the construction of $C_{n+1}$ we obtain that

$$
\phi\left(x_{n+1}, u_{n}\right) \leq \phi\left(x_{n+1}, x_{n}\right)+\eta_{n} \longrightarrow 0 \quad(\text { as } n \longrightarrow \infty) .
$$

From (1.10) it yields $\left(\left\|x_{n+1}\right\|-\left\|u_{n}\right\|\right)^{2} \rightarrow 0$. Since $\left\|x_{n+1}\right\| \rightarrow\|p\|$, we have

$$
\left\|u_{n}\right\| \longrightarrow\|p\| \quad(\text { as } n \longrightarrow \infty)
$$

Hence we have

$$
\left\|J u_{n}\right\| \longrightarrow\|J p\| \quad(\text { as } n \longrightarrow \infty) .
$$

This implies that $\left\{J u_{n}\right\}$ is bounded in $E^{*}$. Since $E$ is reflexive, and so $E^{*}$ is reflexive, there exists a subsequence $\left\{J u_{n_{i}}\right\} \subset\left\{J u_{n}\right\}$ such that $J u_{n_{i}} \rightarrow p_{0} \in E^{*}$. In view of the reflexive of $E$, we see that $J(E)=E^{*}$. Hence there exists $x \in E$ such that $J x=p_{0}$. Since

$$
\begin{aligned}
\phi\left(x_{n_{i}+1}, u_{n_{i}}\right) & =\left\|x_{n_{i}+1}\right\|^{2}-2\left\langle x_{n_{i}+1}, J u_{n_{i}}\right\rangle+\left\|u_{n_{i}}\right\|^{2} \\
& =\left\|x_{n_{i}+1}\right\|^{2}-2\left\langle x_{n_{i}+1}, J u_{n_{i}}\right\rangle+\left\|J u_{n_{i}}\right\|^{2}
\end{aligned}
$$

taking $\liminf \operatorname{in}_{n \rightarrow \infty}$ on the both sides of above equality and in view of the weak lower semicontinuity of norm $\|\cdot\|$, then it yields that

$$
\begin{aligned}
0 & \geq\|p\|^{2}-2\left\langle p, p_{0}\right\rangle+\left\|p_{0}\right\|^{2}=\|p\|^{2}-2\langle p, J x\rangle+\|J x\|^{2} \\
& =\|p\|^{2}-2\langle p, J x\rangle+\|x\|^{2}=\phi(p, x) .
\end{aligned}
$$

That is $p=x$. This implies that $p_{0}=J p$, and so $J u_{n} \rightarrow J p$. It follows from (3.24) and the Kadec-Klee property of $E^{*}$ that $J u_{n_{i}} \rightarrow J p($ as $n \rightarrow \infty)$. Note that $J^{-1}: E^{*} \rightarrow E$ is hemicontinuous, it yields that $u_{n_{i}} \rightarrow p$. It follows from (3.23) and the Kadec-Klee property of $E$ that $\lim _{n_{i} \rightarrow \infty} u_{n_{i}}=p$.

By the similar way as given in the proof of (3.20), we can also prove that

$$
\lim _{n \rightarrow \infty} u_{n}=p
$$

From (3.20) and (3.27) we have that

$$
\left\|x_{n}-u_{n}\right\| \longrightarrow 0 \quad(\text { as } n \longrightarrow \infty)
$$

Since $J$ is uniformly continuous on any bounded subset of $E$, we have

$$
\left\|J x_{n}-J u_{n}\right\| \longrightarrow 0 \quad(\text { as } n \longrightarrow \infty)
$$


For any $j \geq 1$ and any $u \in \mathcal{F}$, it follows from (3.13), (3.20), and (3.27) that

$$
\alpha_{n} \alpha_{n, 0} \alpha_{n, j} g\left(\left\|J x_{n}-J S_{j}^{n} x_{n}\right\|\right) \leq \phi\left(u, x_{n}\right)-\phi\left(u, u_{n}\right)+\alpha_{n} \eta_{n}
$$

Since

$$
\begin{aligned}
\phi\left(u, x_{n}\right)-\phi\left(u, u_{n}\right) & =\left\|x_{n}\right\|^{2}-\left\|u_{n}\right\|^{2}-2\left\langle u, J x_{n}-J u_{n}\right\rangle \\
& \leq\left|\left\|x_{n}\right\|^{2}-\left\|u_{n}\right\|^{2}\right|+2\|u\| \cdot\left\|J x_{n}-J u_{n}\right\| \\
& \leq\left\|x_{n}-u_{n}\right\|\left(\left\|x_{n}\right\|+\left\|u_{n}\right\|\right)+2\|u\| \cdot\left\|J x_{n}-J u_{n}\right\|
\end{aligned}
$$

from (3.28) and (3.29), it follows that

$$
\phi\left(u, x_{n}\right)-\phi\left(u, u_{n}\right) \longrightarrow 0 \quad(n \longrightarrow \infty)
$$

In view of condition (b) and condition (c), we have that

$$
g\left(\left\|J x_{n}-J S_{j}^{n} x_{n}\right\|\right) \longrightarrow 0 \quad(\text { as } n \longrightarrow \infty)
$$

It follows from the property of $g$ that

$$
\left\|J x_{n}-J S_{j}^{n} x_{n}\right\| \longrightarrow 0, \quad(\text { as } n \longrightarrow \infty)
$$

Since $x_{n} \rightarrow p$ and $J$ is uniformly continuous, it yields $J x_{n} \rightarrow J p$. Hence from (3.34) we have

$$
J S_{j}^{n} x_{n} \longrightarrow J p \quad(\text { as } n \longrightarrow \infty)
$$

Since $J^{-1}: E^{*} \rightarrow E$ is hemicontinuous, it follows that

$$
S_{j}^{n} x_{n} \rightarrow p \quad(\forall j \geq 1)
$$

On the other hand, for each $j \geq 1$ we have

$$
\left|\left\|S_{j}^{n} x_{n}\right\|-\|p\|\right|=\left|\left\|J\left(S_{j}^{n} x_{n}\right)\right\|-\|J p\|\right| \leq\left\|J S_{j}^{n} x_{n}-J p\right\| \longrightarrow 0 \quad(\text { as } n \longrightarrow \infty) .
$$

This together with (3.36) shows that

$$
S_{j}^{n} x_{n} \longrightarrow p \quad(\text { for each } j \geq 1)
$$


Furthermore, by the assumption that for each $j \geq 1, S_{j}$ is uniformly $L_{i}$-Lipschitz continuous, hence we have

$$
\begin{aligned}
\left\|S_{j}^{n+1} x_{n}-S_{j}^{n} x_{n}\right\| \leq & \left\|S_{j}^{n+1} x_{n}-S_{j}^{n+1} x_{n+1}\right\|+\left\|S_{j}^{n+1} x_{n+1}-x_{n+1}\right\| \\
& +\left\|x_{n+1}-x_{n}\right\|+\left\|x_{n}-S_{j}^{n} x_{n}\right\| \\
\leq & \left(L_{j}+1\right)\left\|x_{n+1}-x_{n}\right\|+\left\|S_{j}^{n+1} x_{n+1}-x_{n+1}\right\|+\left\|x_{n}-S_{j}^{n} x_{n}\right\| .
\end{aligned}
$$

This together with (3.20) and (3.38), yields $\left\|S_{j}^{n+1} x_{n}-S_{j}^{n} x_{n}\right\| \rightarrow 0$ (as $\left.n \rightarrow \infty\right)$. Hence from (3.36) we have $S_{j}^{n+1} x_{n} \rightarrow p$, that is, $S_{j} S_{j}^{n} x_{n} \rightarrow p$. In view of (3.38) and the closeness of $S_{j}$, it yields that $S_{j} p=p$, for all $j \geq 1$. This implies that $p \in \bigcap_{i=1}^{\infty} F\left(S_{i}\right)$.

Next, we prove that $p \in \bigcap_{i=1}^{M} \operatorname{GMEP}\left(F_{i}, A_{i}, \psi_{i}\right)$. Denote that

$$
u_{n}^{(m)}=K_{r_{m, n}}^{\Gamma_{m}} K_{r_{m-1, n}}^{\Gamma_{m-1}} \cdots K_{r_{2, n}}^{\Gamma_{2}} K_{r_{1, n}}^{\Gamma_{1}} y_{n}, \quad m=1,2, \ldots, M-1, u_{n}^{(M)}=u_{n} .
$$

By the similar method as in the proof of (3.13), we can prove that

$$
\phi\left(u, u_{n}^{(m)}\right) \leq \phi\left(u, x_{n}\right)+\eta_{n}, \quad m=1,2, \ldots, M, u \in \mathcal{F}, \forall n \geq 1
$$

It follows from Lemma 2.6, (2.15), (3.32) that for any $u \in \mathcal{F}$,

$$
\begin{aligned}
\phi\left(u_{n}^{(M)}, u_{n}^{(M-1)}\right) & =\phi\left(K_{r_{n}}^{\Gamma_{M}} u_{n}^{(M-1)}, u_{n}^{(M-1)}\right) \\
& \leq \phi\left(u, u_{n}^{(M-1)}\right)-\phi\left(u, K_{r_{n}}^{\Gamma_{M}} u_{n}^{(M-1)}\right) \\
& \leq \phi\left(u, x_{n}\right)+\eta_{n}-\phi\left(u, \Gamma_{r_{n}}^{M} u_{n}^{(M-1)}\right) \\
& =\phi\left(u, x_{n}\right)+\eta_{n}-\phi\left(u, u_{n}^{(M)}\right) \\
& \left.=\phi\left(u, x_{n}\right)+\eta_{n}-\phi\left(u, u_{n}\right) \longrightarrow 0 \quad \text { (as } n \longrightarrow \infty\right) .
\end{aligned}
$$

From (1.10) it yields $\left(\left\|u_{n}^{(M)}\right\|-\left\|u_{n}^{(M-1)}\right\|\right)^{2} \rightarrow 0$. Since $\left\|u_{n}^{(M)}\right\|=\left\|u_{n}\right\| \rightarrow\|p\|$, we have

$$
\left\|u_{n}^{(M-1)}\right\| \longrightarrow\|p\| \quad(\text { as } n \longrightarrow \infty)
$$

Hence we have

$$
\left\|J u_{n}^{(M-1)}\right\| \rightarrow\|J p\| \quad(\text { as } n \longrightarrow \infty) .
$$


This implies that $\left\{J u_{n}^{(M-1)}\right\}$ is bounded in $E^{*}$. Since $E$ is reflexive, and so $E^{*}$ is reflexive, there exists a subsequence $\left\{J u_{n_{i}}^{(M-1)}\right\} \subset\left\{J u_{n}^{(M-1)}\right\}$ such that $J u_{n_{i}}^{(M-1)} \rightarrow p_{0} \in E^{*}$. In view of the reflexive of $E$, we see that $J(E)=E^{*}$. Hence there exists $x \in E$ such that $J x=p_{0}$. Since

$$
\begin{aligned}
\phi\left(u_{n_{i}}^{(M)}, u_{n_{i}}^{(N-1)}\right) & =\left\|u_{n_{i}}^{(M)}\right\|^{2}-2\left\langle u_{n_{i}}^{(M)}, J u_{n_{i}}^{(M-1)}\right\rangle+\left\|u_{n_{i}}^{(M-1)}\right\|^{2} \\
& =\left\|u_{n_{i}}^{(M)}\right\|^{2}-2\left\langle u_{n_{i}}^{(M)}, J u_{n_{i}}^{(M-1)}\right\rangle+\left\|J u_{n_{i}}^{(M-1)}\right\|^{2}
\end{aligned}
$$

taking $\liminf n_{n_{i} \rightarrow \infty}$ on the both sides of above equality and in view of the weak lower semicontinuity of norm $\|\cdot\|$, it yields that

$$
\begin{aligned}
0 & \geq\|p\|^{2}-2\left\langle p, p_{0}\right\rangle+\left\|p_{0}\right\|^{2}=\|p\|^{2}-2\langle p, J x\rangle+\|J x\|^{2} \\
& =\|p\|^{2}-2\langle p, J x\rangle+\|x\|^{2}=\phi(p, x) .
\end{aligned}
$$

This is, $p=x$. This implies that $p_{0}=J p$, and so $J u_{n_{i}}^{(M-1)} \rightarrow J p$. It follows from (3.44) and the Kadec-Klee property of $E^{*}$ that $J u_{n_{i}}^{(M-1)} \rightarrow J p\left(\right.$ as $\left.n_{i} \rightarrow \infty\right)$. Note that $J^{-1}: E^{*} \rightarrow E$ is hemicontinuous it yields that $u_{n_{i}}^{(M-1)} \rightarrow p$. It follows from (3.43) and the Kadec-Klee property of $E$ that $\lim _{n_{i} \rightarrow \infty} u_{n_{i}}^{(M-1)}=p$.

By the similar way as given in the proof of (3.20), we can also prove that

$$
\lim _{n \rightarrow \infty} u_{n}^{(M-1)}=p
$$

From (3.27) and (3.47) we have that

$$
\left\|u_{n}^{(M)}-u_{n}^{(M-1)}\right\| \longrightarrow 0 \quad(\text { as } n \longrightarrow \infty)
$$

Since $J$ is uniformly continuous on any bounded subset of $E$, we have

$$
\left\|J u_{n}^{(M)}-J u_{n}^{(M-1)}\right\| \longrightarrow 0 \quad(\text { as } n \longrightarrow \infty)
$$

Since

$$
u_{n}^{(i)}=K_{r_{n}}^{\Gamma_{i}} u_{n}^{(i-1)}, \quad i=2,3, \ldots, M, u_{n}^{(0)}=y_{n}, u_{n}^{(M)}=u_{n}
$$

By the similar way as above, we can also prove that

$$
\begin{gathered}
u_{n}^{(i)} \rightarrow p, \quad\left\|u_{n}^{(i)}-u_{n}^{(i-1)}\right\| \longrightarrow 0, \quad\left\|J u_{n}^{(i)}-J u_{n}^{(i-1)}\right\| \longrightarrow 0, \quad i=2,3, \ldots, M \\
\left\|y_{n}-u_{n}^{(1)}\right\| \longrightarrow 0, \quad\left\|J y_{n}-J u_{n}^{(1)}\right\| \longrightarrow 0 \quad(\text { as } n \longrightarrow \infty) .
\end{gathered}
$$


From (3.51) and the assumption that $r_{n} \geq d, \forall n \geq 0$, we have

$$
\lim _{n \rightarrow \infty} \frac{\left\|J u_{n}^{(i)}-J u_{n}^{(i-1)}\right\|}{r_{i, n}}=0, \quad i=2,3, \ldots, M ; \quad \lim _{n \rightarrow \infty} \frac{\left\|J y_{n}-J u_{n}^{(1)}\right\|}{r_{1, n}}=0
$$

In the proof of Lemma 2.6 we have proved that the function $\Gamma_{i}, i=1,2, \ldots, M$ defined by (3.6) satisfies the condition (A1)-(A4) and

$$
\Gamma_{i}\left(u_{n}^{(i)}, y\right)+\frac{1}{r_{i, n}}\left\langle y-u_{n}^{(i)}, J u_{n}^{(i)}-J u_{n}^{(i-1)}\right\rangle \geq 0, \quad \forall y \in C
$$

Therefore for any $y \in C$ we have

$$
\frac{1}{r_{i, n}}\left\langle y-u_{n}^{(i)}, J u_{n}^{(i)}-J u_{n}^{(i-1)}\right\rangle \geq-\Gamma_{i}\left(u_{n}^{(i)}, y\right) \geq \Gamma_{i}\left(y, u_{n}^{(i)}\right) .
$$

This implies that

$$
\begin{aligned}
\Gamma_{i}\left(y, u_{n}^{(i)}\right) & \leq \frac{1}{r_{i, n}}\left\langle y-u_{n}^{(i)}, J u_{n}^{(i)}-J u_{n}^{(i-1)}\right\rangle \\
& \leq\left(M_{1}+\|y\|\right) \frac{\left\|J u_{n}^{i}-J u_{n}^{(i-1)}\right\|}{r_{i, n}}
\end{aligned}
$$

for some constant $M_{1}>0$. Since the function $y \mapsto \Gamma_{i}(x, y)$ is convex and lower semicontinuous, letting $n \rightarrow \infty$ in (3.55), from (3.52) and (3.55), for each $i$, we have $\Gamma_{i}(y, p) \leq$ 0 , for all $y \in C$.

For $t \in(0,1]$ and $y \in C$, letting $y_{t}=t y+(1-t) p$, there are $y_{t} \in C$ and $\Gamma_{i}\left(y_{t}, p\right) \leq 0$. By condition (A1) and (A4), we have

$$
0=\Gamma_{i}\left(y_{t}, y_{t}\right) \leq t \Gamma_{i}\left(y_{t}, y\right)+(1-t) \Gamma_{i}\left(y_{t}, p\right) \leq t \Gamma_{i}\left(y_{t}, y\right)
$$

Dividing both sides of the above equation by $t$, we have $\Gamma_{i}\left(y_{t}, y\right) \geq 0$, for all $y \in C$. Letting $t \downarrow 0$, from condition $(A 3)$, we have $\Gamma_{i}(p, y) \geq 0$, for all $y \in C$, for all $i=1,2, \ldots, M$, that is, for each $i=1,2, \ldots, M$, we have

$$
F_{i}(p, y)+\left\langle A_{i} p, y-p\right\rangle+\psi_{i}(y)-\psi_{i}(p) \geq 0, \quad \forall y \in C .
$$

This implies that $p \in \bigcap_{j=1}^{M} \operatorname{GMEP}\left(F_{j}, A_{j}, \psi_{j}\right)$. Therefore, we have that

$$
p \in \mathbb{F} \text {. }
$$

(V) Now, we prove $x_{n} \rightarrow \Pi_{\mp} x_{0}$. 
Let $w=\Pi_{\mp} x_{0}$. From $w \in \mathcal{F} \subset C_{n+1}$ and $x_{n+1}=\prod_{C_{n+1}} x_{0}$, we have $\phi\left(x_{n+1}, x_{0}\right) \leq \phi\left(w, x_{0}\right)$, for all $n \geq 0$. This implies that

$$
\phi\left(p, x_{0}\right)=\lim _{n \rightarrow \infty} \phi\left(x_{n}, x_{0}\right) \leq \phi\left(w, x_{0}\right)
$$

By the definition of $\Pi_{\mp} x_{0}$ and (3.59), we have $p=w$. Therefore, $x_{n} \rightarrow \Pi_{\mp} x_{0}$. This completes the proof of Theorem 3.1.

Theorem 3.2. Let $E, C,\left\{K_{r_{i, n}}^{\Gamma_{i}}\right\}_{i=1}^{M},\left\{A_{i}\right\}_{i=1}^{M},\left\{F_{i}\right\}_{i=1}^{M},\left\{\psi_{i}\right\}_{i=1}^{M},\left\{\operatorname{GMEP}\left(F_{j}, A_{j}, \psi_{j}\right)\right\}_{j=1}^{M}$ be the same as above. Let $\left\{S_{i}\right\}_{i=1}^{\infty}: C \rightarrow C$ be an infinite family of closed and uniformly quasi- $\phi$-asymptotically nonexpansive mappings with a sequence $\left\{k_{n}\right\} \subset[1, \infty)$ and $k_{n} \rightarrow 1$. Suppose that for each $i \geq 1, S_{i}$ is uniformly $L_{i}$-Lipschitz continuous and that

$$
\mathcal{G}:=\bigcap_{i=1}^{\infty} F\left(S_{i}\right) \bigcap \bigcap_{j=1}^{M} \operatorname{GMEP}\left(F_{j}, A_{j}, \psi_{j}\right)
$$

is a nonempty and bounded subset of $C$. For any given $x_{0} \in C$, let $\left\{x_{n}\right\}$ be the sequence generated by

$$
\begin{aligned}
& x_{0} \in C_{0}=C, \\
& z_{n}=J^{-1}\left(\alpha_{n, 0} J x_{n}+\sum_{i=1}^{\infty} \alpha_{n, i} J S_{i}^{n} x_{n}\right), \\
& y_{n}=J^{-1}\left(\alpha_{n} J z_{n}+\left(1-\alpha_{n}\right) J x_{n}\right), \\
& u_{n}=K_{r_{M, n}}^{\Gamma_{M}} K_{r_{M-1, n}}^{\Gamma_{M-1}} \cdots K_{r_{2, n}}^{\Gamma_{2}} K_{r_{1, n}}^{\Gamma_{1}} y_{n}, \\
& C_{n+1}=\left\{v \in C_{n}: \phi\left(v, u_{n}\right) \leq \phi\left(v, x_{n}\right)+\xi_{n}\right\}, \\
& x_{n+1}=\prod_{C_{n+1}} x_{0}, \quad \forall n \geq 0,
\end{aligned}
$$

where $\xi_{n}=\sup _{u \in \mathcal{G}}\left(k_{n}-1\right) \phi\left(u, x_{n}\right), r_{n} \in[d, \infty)$ for some $d>0$, and for $i \geq 0,\left\{\alpha_{n, i}\right\},\left\{\alpha_{n}\right\}$ are sequences in $[0,1]$ satisfying the following conditions:

(a) $\sum_{i=0}^{\infty} \alpha_{n, i}=1$ for all $n \geq 0$;

(b) $\liminf _{n \rightarrow \infty} \alpha_{n, 0} \cdot \alpha_{n, i}>0$ for all $i \geq 1$;

(c) $0<\alpha \leq \alpha_{n}<1$ for some $\alpha \in(0,1)$.

Then $\left\{x_{n}\right\}$ converges strongly to $\Pi_{\mathcal{G}} x_{0}$.

Proof. Since $\left\{S_{i}\right\}_{i=1}^{\infty}: C \rightarrow C$ is an infinite family of closed quasi- $\phi$-asymptotically nonexpansive mappings, it is an infinite family of closed and uniformly total quasi- $\phi$ asymptotically nonexpansive mappings with sequence $\zeta(t)=t, t \geq 0, v_{n}=k_{n}-1, \mu_{n}=0$. Hence $\zeta_{n}=v_{n} \sup _{u \in \mathcal{G}} \zeta\left(\phi\left(u, x_{n}\right)\right)+\mu_{n}=\sup _{u \in \mathcal{G}}\left(k_{n}-1\right) \phi\left(u, x_{n}\right) \rightarrow 0$. Therefore all conditions in Theorem 3.1 are satisfied. The conclusion of Theorem 3.2 is obtained from Theorem 3.1 immediately. 
Remark 3.3. Theorems 3.1 and 3.2 improve and extend the corresponding results in $[8,11,15$, $16,18-24,28]$ and others in the following aspects.

(a) For the framework of spaces, we extend the space from a uniformly smooth and uniformly convex Banach space to a uniformly smooth and strictly convex Banach space with the Kadec-Klee property (note that each uniformly convex Banach space must have Kadec-Klee property).

(b) For the mappings, we extend the mappings from nonexpansive mappings, relatively nonexpansive mappings, quasi- $\phi$-nonexpansive mapping or quasi- $\phi$ asymptotically nonexpansive mappings to a countable family of total quasi- $\phi$ asymptotically nonexpansive mappings.

(c) We extend a single generalized mixed equilibrium problem to a system of generalized mixed equilibrium problems.

\section{Acknowledgments}

This work was supported by Scientific Reserch Fund of Sichuan Provincial Education Department (09zb102, 11zb146) and the Natural Science Foundation of Yibin University and Yunnan University of Finance and Economics.

\section{References}

[1] S.-S. Chang, H. W. J. Lee, and C. K. Chan, "A new hybrid method for solving a generalized equilibrium problem, solving a variational inequality problem and obtaining common fixed points in Banach spaces, with applications," Nonlinear Analysis: Theory, Methods E Applications, vol. 73, no. 7, pp. 2260-2270, 2010.

[2] L.-C. Ceng and J.-C. Yao, "A hybrid iterative scheme for mixed equilibrium problems and fixed point problems," Journal of Computational and Applied Mathematics, vol. 214, no. 1, pp. 186-201, 2008.

[3] J. Tang and S.-S. Chang, "Strong convergence theorem for a generalized mixed equilibrium problem and fixed point problem for a family of infinitely nonexpansive mappings in Hilbert spaces," Panamerican Mathematical Journal, vol. 19, no. 2, pp. 75-86, 2009.

[4] E. U. Ofoedu and D. M. Malonza, "Hybrid approximation of solutions of nonlinear operator equations and application to equation of Hammerstein-type," Applied Mathematics and Computation, vol. 217, no. 13, pp. 6019-6030, 2011.

[5] S.-s. Zhang, "Generalized mixed equilibrium problem in Banach spaces," Applied Mathematics and Mechanics. English Edition, vol. 30, no. 9, pp. 1105-1112, 2009.

[6] I. Cioranescu, Geometry of Banach Spaces, Duality Mappings and Nonlinear Problems, vol. 62 of Mathematics and Its Applications, Kluwer Academic Publishers Group, Dordrecht, The Netherlands, 1990.

[7] Y. I. Alber, "Metric and generalized projection operators in Banach spaces: properties and applications," in Theory and Applications of Nonlinear Operators of Accretive and Monotone Type, vol. 178 of Lecture Notes in Pure and Appl. Math., pp. 15-50, Dekker, New York, NY, USA, 1996.

[8] S.-y. Matsushita and W. Takahashi, "A strong convergence theorem for relatively nonexpansive mappings in a Banach space," Journal of Approximation Theory, vol. 134, no. 2, pp. 257-266, 2005.

[9] Y. Su, H.-k. Xu, and X. Zhang, "Strong convergence theorems for two countable families of weak relatively nonexpansive mappings and applications," Nonlinear Analysis: Theory, Methods $\mathcal{E}$ Applications, vol. 73, no. 12, pp. 3890-3906, 2010.

[10] W. Nilsrakoo and S. Saejung, "Strong convergence to common fixed points of countable relatively quasi-nonexpansive mappings," Fixed Point Theory and Applications, vol. 2008, Article ID 312454, 19 pages, 2008. 
[11] H. Zhou, G. Gao, and B. Tan, "Convergence theorems of a modified hybrid algorithm for a family of quasi- $\varphi$-asymptotically nonexpansive mappings," Journal of Applied Mathematics and Computing, vol. 32, no. 2, pp. 453-464, 2010.

[12] S.-Y. Matsushita and W. Takahashi, "A strong convergence theorem for relatively nonexpansive mappings in a Banach space," Journal of Approximation Theory, vol. 134, no. 2, pp. 257-266, 2005.

[13] Y. Su, H.-K. Xu, and X. Zhang, "Strong convergence theorems for two countable families of weak relatively nonexpansive mappings and applications," Nonlinear Analysis: Theory, Methods $\mathcal{E}$ Applications, vol. 73, no. 12, pp. 3890-3906, 2010.

[14] H. Zegeye and N. Shahzad, "Strong convergence theorems for monotone mappings and relatively weak nonexpansive mappings," Nonlinear Analysis: Theory, Methods E Applications, vol. 70, no. 7, pp. 2707-2716, 2009.

[15] K. Wattanawitoon and P. Kumam, "Strong convergence theorems by a new hybrid projection algorithm for fixed point problems and equilibrium problems of two relatively quasi-nonexpansive mappings," Nonlinear Analysis: Hybrid Systems, vol. 3, no. 1, pp. 11-20, 2009.

[16] X. Qin, S. Y. Cho, and S. M. Kang, "On hybrid projection methods for asymptotically quasi- $\phi$ nonexpansive mappings," Applied Mathematics and Computation, vol. 215, no. 11, pp. 3874-3883, 2010.

[17] W. Takahashi and K. Zembayashi, "Strong and weak convergence theorems for equilibrium problems and relatively nonexpansive mappings in Banach spaces," Nonlinear Analysis: Theory, Methods $\mathcal{E}$ Applications, vol. 70, no. 1, pp. 45-57, 2009.

[18] S.-S. Chang, J. K. Kim, and X. R. Wang, "Modified block iterative algorithm for solving convex feasibility problems in Banach spaces," Journal of Inequalities and Applications, vol. 2010, Article ID 869684, 14 pages, 2010.

[19] S.-s. Chang, X. R. Wang, H. W. J. Lee, and C. K. Chan, "Strong convergence theorems for asymptotically relatively nonexpansive mappings with application," Communications on Applied Nonlinear Analysis, vol. 18, no. 1, pp. 45-60, 2011.

[20] Y. Yao, Y. J. Cho, and Y.-C. Liou, "Iterative algorithms for variational inclusions, mixed equilibrium and fixed point problems with application to optimization problems," Central European Journal of Mathematics, vol. 9, no. 3, pp. 640-656, 2011.

[21] Y. Yao, Y. J. Cho, and Y.-C. Liou, "Algorithms of common solutions for variational inclusions, mixed equilibrium problems and fixed point problems," European Journal of Operational Research, vol. 212, no. 2, pp. 242-250, 2011.

[22] X. Qin, S.-S. Chang, and Y. J. Cho, "Iterative methods for generalized equilibrium problems and fixed point problems with applications," Nonlinear Analysis: Real World Applications, vol. 11, no. 4, pp. 2963 2972, 2010.

[23] Y. J. Cho, I. K. Argyros, and N. Petrot, "Approximation methods for common solutions of generalized equilibrium, systems of nonlinear variational inequalities and fixed point problems," Computers $\mathcal{E}$ Mathematics with Applications, vol. 60, no. 8, pp. 2292-2301, 2010.

[24] Y. J. Cho, X. Qin, and J. I. Kang, "Convergence theorems based on hybrid methods for generalized equilibrium problems and fixed point problems," Nonlinear Analysis: Theory, Methods E Applications, vol. 71, no. 9, pp. 4203-4214, 2009.

[25] H. Zhang and Y. Su, "Strong convergence of modified hybrid algorithm for quasi- $\phi$-asymptotically nonexpansive mappings," Korean Mathematical Society. Communications, vol. 24, no. 4, pp. 539-551, 2009.

[26] S. Kamimura and W. Takahashi, "Strong convergence of a proximal-type algorithm in a Banach space," SIAM Journal on Optimization, vol. 13, no. 3, pp. 938-945, 2002.

[27] E. Blum and W. Oettli, "From optimization and variational inequalities to equilibrium problems," The Mathematics Student, vol. 63, no. 1-4, pp. 123-145, 1994.

[28] W. Takahashi and K. Zembayashi, "Strong and weak convergence theorems for equilibrium problems and relatively nonexpansive mappings in Banach spaces," Nonlinear Analysis: Theory, Methods $\mathcal{E}$ Applications, vol. 70, no. 1, pp. 45-57, 2009. 


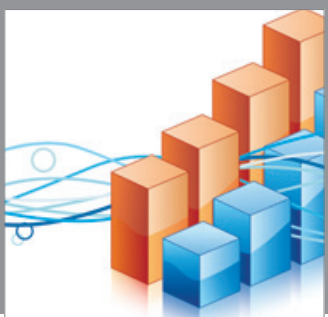

Advances in

Operations Research

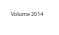

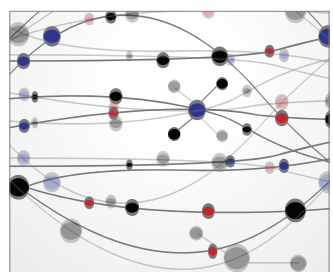

\section{The Scientific} World Journal
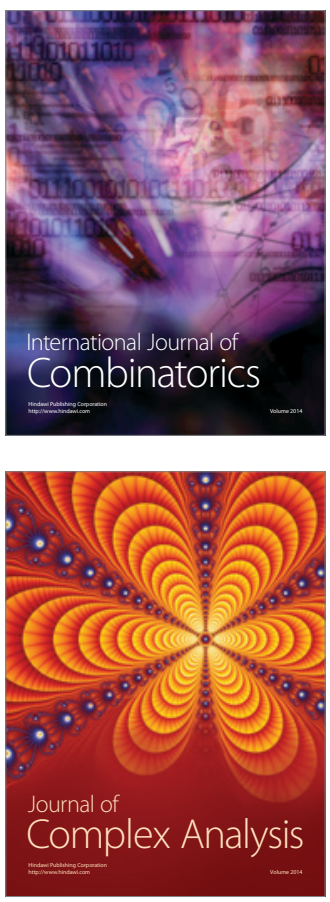

International Journal of

Mathematics and

Mathematical

Sciences
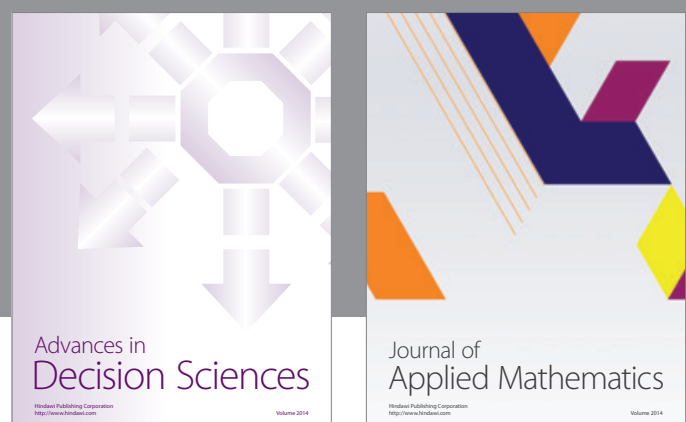

Journal of

Applied Mathematics
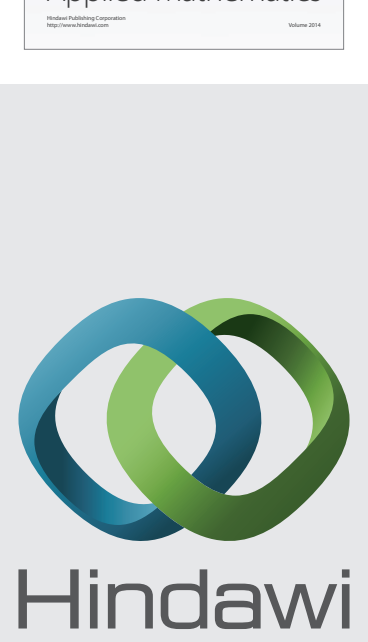

Submit your manuscripts at http://www.hindawi.com
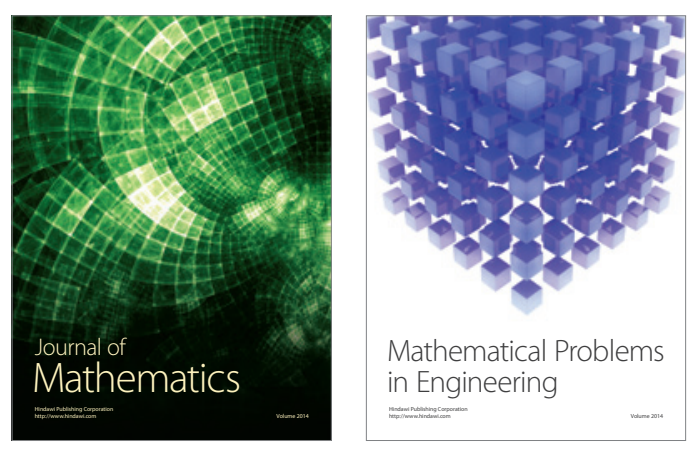

Mathematical Problems in Engineering
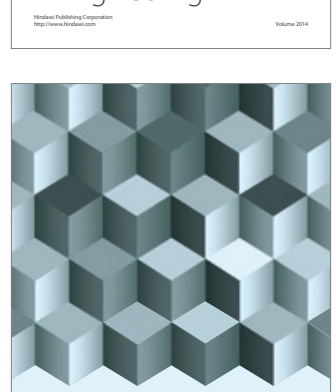

Journal of

Function Spaces
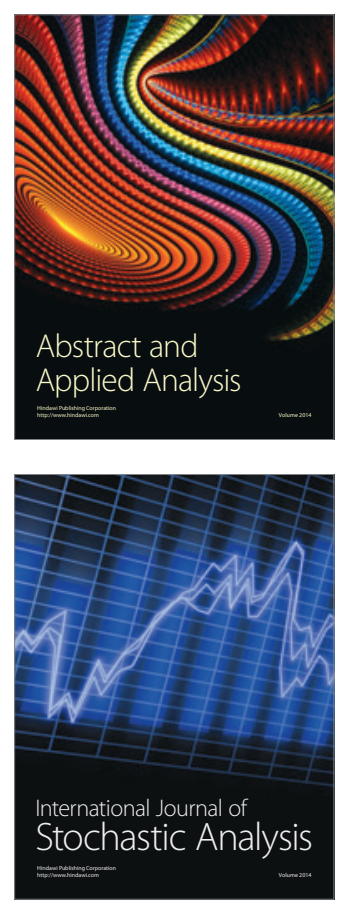

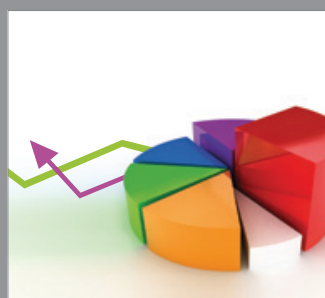

ournal of

Probability and Statistics

Promensencen
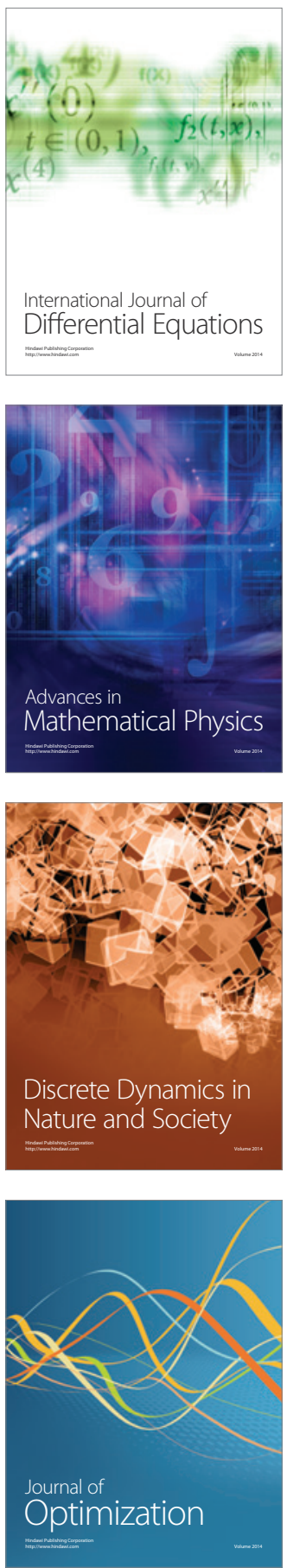